УДК 616-006.6

14.00.00 Медицинские науки

РОЛЬ ФАКТОРОВ ТРАНСКРИПЦИИ И АНГИОГЕНЕЗА В ПАТОГЕНЕЗЕ ГНОЙНЫХ ПОСЛЕОПЕРАЦИОННЫХ ОСЛОЖНЕНИЙ У БОЛЬНЫХ РАКОМ СЛИЗИСТОЙ ОБОЛОЧКИ ПОЛОСТИ РТА

Кит Олег Иванович

д.м.н., член-корр РАН, профессор, директор РИНЦ SPIN-код: 1728-0329

Scopus ID: 55994103100

Кононенко Владимир Иванович

к.м.н., доцент, заведующий кафедрой

РИНЦ SPIN-код: 8699-8320

Максюков Станислав Юрьевич

д.м.н., доцент, заведующий кафедрой

РИНЦ SPIN-код: 8542-8660

Scopus ID:

Комарова Екатерина Федоровна

д.б.н., профессор РАН, главный научный

сотрудник

РИНЦ SPIN-код: 1094-3139

Scopus ID: 55890096600

Максимов Алексей Юрьевич

д.м.н., профессор, заместитель директора РИНЦ SPIN-код: 7322-5589

Дашкова Ирина Рудольфовна д.м.н., профессор РАН, главный научный сотрудник

Позднякова Виктория Вадимовна

Д.м.н., профессор, ведущий научный сотрудник РИНЦ SPIN-код: 7306-2034

Scopus ID: 54380529400

Новикова Инна Арнольдовна

к.м.н., руководитель лаборатории

РИНЦ SPIN-код: 4810-2424

Scopus ID: 7005153343

Демидова Александра Александровна

к.м.н., доцент

РИНЦ SPIN-код: 4014-8502

Scopus ID: 7006838349

ФГБУ "Ростовский научно-исследовательский онкологический институт" Министерства здравоохранения РФ, Россия, 344037, Ростов-наДону, ул. 14-я линия, 63

ФГБОУ ВО РостГМУ Минздрава России, Россия, 344022, Ростов-на-Дону, ул. Нахичеванский 29
UDC 616-006.6

Medical sciences

\section{THE ROLE OF THE TRANSCRIPTION AND \\ ANGIOGENESIS FACTORS IN THE \\ PATHOGENESIS OF PURULENT \\ POSTOPERATIVE COMPLICATIONS IN PATIENTS WITH ORAL MUCOSA CANCER}

Kit Oleg Ivanovich

Dr.Sci.Med., corresponding member of RAS, professor, director

RSCI SPIN code: 1728-0329

Scopus ID: 55994103100

Kononenko Vladimir Ivanovich

MD, assistant professor, head of department

RSCI SPIN code: $8699-8320$

Maksyukov Stanislav Yur'evich

Dr. Sci. Med., assistant professor, head of department RSCI SPIN code: $8542-8660$

Komarova Ekaterina Fedorovna

Dr. Sci.Biol., professor RAS, Chief Researcher RSCI SPIN code: 1094-3139

Scopus ID: 55890096600

Maksimov Aleksey Yurievich

Dr. Sci. Med., professor, deputy director

RSCI SPIN-code: 7322-5589

Dashkova Irina Ryudol'fovna

Dr. Sci. Med., professor RAS, Leading Researcher

Pozdnyakova Victoria Vadimovna

Dr. Sci. Med., professor, Leading Researcher

RSCI SPIN code: 7306-2034

Scopus ID: 54380529400

Novikova Inna Arnol'dovna

Cand.Med.Sci., head of laboratory

RSCI SPIN-code: 4810-2424

Scopus ID: 7005153343

Demidova Alexandra Alexandrovna

Cand.Med.Sci., assistant professor

RSCI SPIN-code: 4014-8502

Scopus ID: 7006838349

Rostov Research Institute of Oncology, Russia,

344037, Rostov-on-Don, 14-line 63

Rostov State Medical University, Russia, 344022,

Rostov-on-Don, Nakhichevanskaya, 29 
При изучении содержания гипоксияиндуцибельного фактора 1-альфа и васкулоэндотелиального ростового фактора в ткани опухоли, ротовой жидкости и периферической крови 141 больного раком слизистой оболочки полости рта Т1-3N0-2M0 показано, что развитие гнойных воспалительных послеоперационных осложнений у больных раком СОПР сопряжено с повышением экспрессии в ткани HIF-1 $\alpha$ и его перемещение из цитоплазмы в ядро, активация процессов неоангиогенеза. Информативным является определение HIF-1 $\alpha$ фактора в сыворотке крови, что, при дальнейшей разработке, может быть использовано как неинвазивный диагностический маркер для прогнозирования течения послеоперационного периода у этой категории больных

Ключевые слова: РАК СЛИЗИСТОЙ ОБОЛОЧКИ ПОЛОСТИ РТА, ГНОЙНЫЕ

ПОСЛЕОПЕРАЦИОННЫЕ ОСЛОЖНЕНИЯ, НІF1A, VEGF, ТКАНЬ ОПУХОЛИ, РОТОВАЯ ЖИДКОСТЬ, ПЕРИФЕРИЧЕСКАЯ КРОВЬ
While studying the content of hypoxia-inducible factor 1-alpha and vascular endothelial growth factor in the tumor tissue, oral fluid and peripheral blood of 141 patients with oral mucosa cancer T1-3N0-2M0, it was shown that the development of purulent inflammatory postoperative complications in patients with oral mucosa cancer is associated with an increased expression of HIF-1 $\alpha$ in the tissue and its translocation from the cytoplasm to the nucleus, activation of the neoangiogenesis processes. It is informative to determine HIF-1 $\alpha$ factor in the blood serum, which, for further development, can be used as a non-invasive diagnostic marker to predict the postoperative course in this category of patients

Keywords: ORAL MUCOSA CANCER, PURULENT POSTOPERATIVE COMPLICATIONS, HIF- $1 \alpha$, VEGF, TUMOUR TISSUE, ORAL FLUID, PERIPHERAL BLOOD

Doi: 10.21515/1990-4665-128-023

\section{Введение.}

В настоящее время существуют сведения о диагностической значимости для прогнозирования течения рака слизистой оболочки полости рта (СОПР) кислород-зависимых факторов, которые активируются при гипоксии и запускают в дальнейшем транскрипционную коактивацию в клетках [1]. Известно, что гипоксия индуцибельный транскрипционный фактор 1-альфа (HIF-1 $\alpha)$, активируясь в физиологически важных местах регуляции кислородных путей, обеспечивает ответы на гипоксический стресс и включает гены, регулирующие процесс ангиогенеза и апоптоза $[3,5,7,9]$.

Посредством стимуляции соответствующих генов HIF- $\alpha$ при гипоксии играет ключевую роль в усилении продукции васкулоэндотелиального фактора роста (VEGF) $[4,6]$. Удаление HIF1 $\alpha$ гена или нарушение транскрипции HIF1 $\alpha$ приводит к отсутствию VEGF секреции клетками опухоли. В результате подавляется ангиогенез и задерживается рост солидных опухолей [4]. Shang Z.J. et al. [10]( также 
было доказано, что продукция VEGF клетками плоскоклеточной карциномы СОПР зависит от уровня $\mathrm{pO}_{2}$ в ткани.

Кроме того, повышенная активность HIF-1 $\alpha$ содействует синтезу защитных факторов биологических жидкостей и увеличивает их бактерицидную активность, обеспечивает усиление реакций врожденного иммунитета на микробную инфекцию [2,9,11].

Такая тесная взаимозависимость всех описанных выше факторов определила цель нашего исследования в выявлении участия HIF- $1 \alpha$ и VEGF в развитии гнойных послеоперационных осложнениях у больных раком слизистой оболочки полости рта.

Материалы и методы. В исследование были включены 141 больной раком слизистой оболочки полости рта Т1-3N0-2М0 стадии процесса.

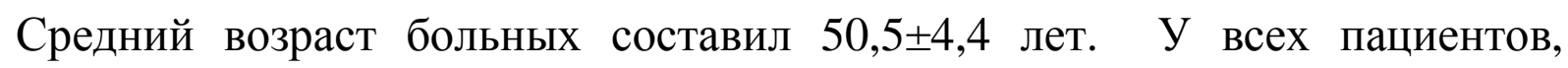
включенных в работу, диагноз плоскоклеточного рака слизистой оболочки полости рта был подтвержден при гистологическом исследовании биопсийного материала. Проведение данной работы было одобрено этическим комитетом ФГБУ «РНИОИ» МЗ РФ. В каждом конкретном случае было получено добровольное информированное согласие больных на использование материалов для проведения научных исследований.

Больные были разделены на 2 группы, у которых в послеоперационном периоде развивались гнойно-воспалительные осложнения (некроз мышечного или кожно-жирового лоскута, используемого для пластики, остеомиелит нижней челюсти, флегмона нижней челюсти) - основная группа (n=96) и послеоперационный период протекал без гнойно-септических осложнений - группа сравнения $(\mathrm{n}=45)$. Группу здоровых доноров составили 35 пациентов стоматологических отделений общего профиля, обратившихся по поводу установки зубных имплантов. 
Были изучены ткани опухоли, взятые во время оперативного вмешательства, которые подвергали дальнейшему замораживанию при температуре $-80^{\circ} \mathrm{C}$. Образцы опухолевой ткани для иммуногистохимического исследования готовили по стандартной методике. Забор ротовой жидкости (свободной нестимулированной слюны) производили в утренние часы до приема пищи после прополаскивания полости рта кипяченой водой. Периферическую кровь для исследования собирали стандартно, натощак.

Уровень экспрессии гипоксия-индуцибельного фактора-1 $\alpha$ (HIF-1 $\alpha$; USCN Life Science) и VEGF-A («BioVision, Incorp.») исследовали методом ИФА. Для выявления белка HIF-1а был применен иммунопероксидазный метод (EnVision/HRP, «Dako Cytomation»), а для оценки экспрессии HIF$1 \alpha$ количество позитивных клеток подсчитывали на 1000 клеток.

Данные обрабатывались при помощи пакета статистических программ «STATISTICA 10.0». При этом соблюдались общие рекомендации для медицинских исследований.

\section{Результаты исследования и их обсуждение.}

Ретроспективно у пациентов с раком СОПР, разделенных по принципу наличия или отсутствия гнойно-воспалительных осложнений, оценивали исходный уровень содержания транскрипционного фактора HIF-1 $\alpha$ и VEGF-A в тканевом гомогенате опухоли, полученном из операционного биоптата (табл. 1). У пациентов при развитии гнойновоспалительных осложнений в ткани опухоли повышалось содержание HIF-1 $\alpha$ (на 38,7\%, p<0,05). Фактор VEGF-A, способствующий росту сосудов и ангиогенезу в опухоли, у пациентов основной группы по сравнению с группой сравнения также был повышен на $21 \%$ ( $<<0,05)$, что, возможно, было следствием накопления HIF-1 $\alpha$.

Таблица 1. 
Содержание HIF-1 $\alpha$ и VEGF-A в опухолевой ткани больных исследуемых групп

\begin{tabular}{|l|c|c|c|c|}
\hline Показатель & $\begin{array}{c}\text { Основная } \\
\text { группа, } \mathrm{n=96}\end{array}$ & $\begin{array}{c}\text { Группа } \\
\text { сравнения, } \\
\mathrm{n}=45\end{array}$ & $\begin{array}{c}\text { В общем по } \\
\text { группе }\end{array}$ & $\mathrm{p}_{\text {осн-срав }}$ \\
\hline $\begin{array}{l}\text { HIF-1 } \alpha, \text { УЕ/мг } \\
\text { белка в лунке }\end{array}$ & $12,9 \pm 0,7$ & $9,3 \pm 0,6$ & $11,5 \pm 4,2$ & $<0,05$ \\
\hline VEGF-A, пг/мг & $90,3 \pm 1,5$ & $74,6 \pm 1,7$ & $82,6 \pm 5,7$ & $<0,05$ \\
\hline
\end{tabular}

Распределение величин содержания HIF-1 $\alpha$ в тканевом гомогенате опухоли у больных основной группы и группы сравнения оценивали с учетом размеров опухоли (табл. 2).

Таблица 2.

Распределение величин НIF-1 $\alpha$ в тканевом гомогенате опухоли (УЕ/ мг белка в лунке) больных исследуемых групп

\begin{tabular}{|l|c|c|c|c|}
\hline $\begin{array}{l}\text { Размер } \\
\text { опухоли }\end{array}$ & $\begin{array}{c}\text { Основная } \\
\text { группа, } \mathrm{n=96}\end{array}$ & $\begin{array}{c}\text { Группа } \\
\text { сравнения, } \mathrm{n}=45\end{array}$ & $\begin{array}{c}\text { В общем по } \\
\text { группе }\end{array}$ & $\begin{array}{c}\mathrm{p}_{\text {осн- }} \\
\text { срав }\end{array}$ \\
\hline T1N0M0 & $9,4 \pm 0,78$ & $8,7 \pm 0,47$ & $9,1 \pm 1,18$ & $>0,05$ \\
\hline $\begin{array}{l}\text { T2N0- } \\
\text { 2M0 }\end{array}$ & $12,2 \pm 0,85$ & $9,1 \pm 0,39$ & $10,7 \pm 0,65$ & $<0,05$ \\
\hline T3N0- & $13,7 \pm 0,72$ & $9,8 \pm 0,53$ & $11,7 \pm 0,55$ & $<0,05$ \\
\hline 2M0 & & & & \\
\hline
\end{tabular}

При размере опухоли Т1 содержание HIF-1 $\alpha$ в ткани было сходным $(\mathrm{p}>0,05)$. При Т2 уровень изучаемого гипоксия-зависимого транскрипционного фактора в опухолевом гомогенате в основной группе был выше по сравнению с группой сравнения на $34 \%$ (p<0,05), а при Т3 на $39,8 \%(p<0,05)$. Как в основной, так и в группе сравнения по мере 
повышения размера опухоли содержание HIF- $1 \alpha$ в тканевом гомогенате опухоли возрастало. Однако, в основной группе градиент роста транскрипционного фактора от Т1 до Т3 был более выраженным, чем в группе сравнения.

Характеристика экспрессии HIF-1 $\alpha$ в опухолевой ткани у больных основной группы и группы сравнения по результатам ИГХ исследования представлена в таблице 3.

Таблица 3.

Характеристика экспрессии HIF-1 $\alpha$ в опухолевой ткани больных исследуемых групп

\begin{tabular}{|c|c|c|c|c|c|}
\hline & \multicolumn{4}{|c|}{ Уровень экспрессии HIF- $1 \alpha$} & \multirow[t]{2}{*}{ Всего } \\
\hline & 0 & $1+$ & $2++$ & $3+++$ & \\
\hline \multicolumn{6}{|c|}{ Основная группа, n=96 } \\
\hline T1N0M0 & - & $3(27,3 \%)^{*}$ & $7(63,6 \%)$ & $1(9,1 \%)$ & $11(100 \%)$ \\
\hline T2N0-2M0 & - & $7(18,9 \%)^{*}$ & $\begin{array}{c}25 \\
(67,6 \%)^{*}\end{array}$ & $5(13,5 \%)$ & $37(100 \%)$ \\
\hline T3N0-2M0 & - & $2(4,2 \%)^{*}$ & $36(75 \%)^{*}$ & $10(20,8 \%)$ & $48(100 \%)$ \\
\hline \multicolumn{6}{|c|}{ Группа сравнения, $\mathrm{n}=45$} \\
\hline T1N0M0 & $\begin{array}{c}1 \\
(16,7 \%)\end{array}$ & $5(83,3 \%)$ & - & - & $6(100 \%)$ \\
\hline T2N0-2M0 & $1(5,6 \%)$ & $12(66,7 \%)$ & $3(16,7 \%)$ & $2(11,1 \%)$ & $18(100 \%)$ \\
\hline T3N0-2M0 & - & $12(57,1 \%)$ & $6(28,6 \%)$ & $3(14,3 \%)$ & $21(100 \%)$ \\
\hline
\end{tabular}

Примечание: * - достоверное отличие между группами при $\mathrm{p}<0,05$.

При размере опухоли Т1 у больных основной группы преобладал средний уровень опухолевой экспрессии (2++) (63,6\%), а у пациентов группы сравнения - слабый уровень опухолевой экспрессии (1+) (83,3\%). Та же самая закономерность прослеживалась и при размере опухоли Т2. У больных основной группы при Т2N0-2M0 средний уровень опухолевой 
экспрессии (2++) встречался в 67,6\% и был чаще других, а у пациентов группы сравнения - слабый уровень опухолевой экспрессии (1+) $(66,7 \%)$ преобладал по частоте. При Т2N0-2M0 сильная экспрессия фактора (3+++) в основной группе встречалась в 13,5\%, а в группе сравнения - в 11,1\%. При Т3N0-2M0 в основной группе средний уровень опухолевой экспрессии (2++), по-прежнему, преобладал (75\%), возросло число опухолевых препаратов, где выраженность экспрессии была сильной $(20,8 \%)$.

В группе сравнения при T3N0-2M0 половина препаратов имела слабый уровень экспрессии HIF-1 $\alpha$ (57,1\%), а другая половина по сумме $(42,9 \%)$ средний и сильный уровень выраженности экспрессии фактора HIF-1 $\alpha$. Таким образом, в основной группе, где развились гнойновоспалительные осложнения, зависимость транскрипционной активности опухолевых клеток от гипоксии была высокой.

Тип окрашивания клеток при ИГХ исследовании экспрессии HIF-1 $\alpha$ в ткани опухоли позволял судить о наличии или отсутствии транслокации фактора в ядро. HIF1 $\alpha$ может перемещаться из цитоплазмы в ядро, где формирует активный HIF-1-комплекс. Таким образом, наличие HIF1 $\alpha$ в ядре ассоциировано с повышением транскрипционной активности клеток.

Характеристики типа окрашивания клеток опухоли у больных основной группы и группы сравнения даны в таблице 4. 
Таблица 4.

Тип окрашивания при экспрессии $\mathrm{HIF}-1 \alpha$ в опухоли больных исследуемых групп

\begin{tabular}{|l|c|c|c||c|c|c|}
\hline \multirow{2}{*}{$\begin{array}{l}\text { Размер } \\
\text { опухоли }\end{array}$} & \multicolumn{4}{|c||}{ Основная групп, $\mathrm{n}=96$} & \multicolumn{3}{|c|}{ Группа сравнения, $\mathrm{n}=45$} \\
\cline { 2 - 7 } & цтм & яд-цтм & всего & цтм & яд-цтм & всего \\
\cline { 2 - 7 } & $\begin{array}{c}6 \\
\text { T1N0M0 }\end{array}$ & $\begin{array}{c}11 \\
(45,5 \%)\end{array}$ & $\begin{array}{c}4 \\
(100 \%)\end{array}$ & $\begin{array}{c}2 \\
(66,7 \%)\end{array}$ & $\begin{array}{c}6 \\
(33,3 \%)^{*}\end{array}$ & $(100 \%)$ \\
\hline T2N0- & 3 & 34 & 37 & 9 & 9 & 18 \\
2M0 & $(8,1 \%)^{\circ}$ & $(91,9 \%)^{* 0}$ & $(100 \%)$ & $(50 \%)$ & $(50 \%)$ & $(100 \%)$ \\
\hline T3N0- & - & 48 & 48 & 5 & 16 & 21 \\
2M0 & $(100 \%)^{\circ}$ & $(100 \%)$ & $(23,8 \%)$ & $(76,2 \%)^{*}$ & $(100 \%)$ \\
\hline
\end{tabular}

Примечание: * - достоверное отличие между типом окрашивания при $\mathrm{p}<0,05,{ }^{\circ}-$ достоверное отличие между группами при $\mathrm{p}<0,05$.

В основной группе ядерно- цитоплазматический тип окрашивания опухолевых клеток при размерах опухоли T1N0M0 наблюдался приблизительно в половине случаев, при Т2N0-2M0 - резко повышался до 91,9\% и при T3N0-2M0 достигал 100\%. В группе сравнения при T1N0M0 ядерно- цитоплазматический тип окрашивания опухолевых клеток имел место в трети случаев (33,3\%), при Т2N0-2М0 - в половине случаев (50\%) и при Т3N0-2M0 в 76,2\%. Следовательно, в основной группе развитие гнойно-септических осложнений было сопряжено с тем, что транслокация HIF-1 $\alpha$ в ядро с активацией транскрипционной активности клеток была выражена сильнее.

Исследование экспрессии транскрипционных факторов (HIF-1 $\alpha$ ) и ростовых факторов (VEGF-A) в ткани опухоли рака COПР сопряжено с инвазивным получением биоптата. Ротовая жидкость является более 
удобной биологической средой для проведения исследования. Определение биомаркеров в свободной нестимулированной слюне является новым подходом к ранней диагностике злокачественых опухолей челюстно-лицевой области, к прогнозированию их рецидивирования и метастазирования. Уровни HIF-1 и VEGF в ротовой жидкости у больных основной группы и группы сравнения отражены в таблице 5.

Таблица 5.

Содержание HIF-1 $\alpha$ и VEGF в ротовой жидкости и периферической крови у пациентов исследуемых групп.

\begin{tabular}{|l|c|c|c|c|}
\hline Показатель & $\begin{array}{c}\text { Основная } \\
\text { группа, } \mathrm{n=96}\end{array}$ & $\begin{array}{c}\text { Группа } \\
\text { сравнения, } \\
\mathrm{n}=45\end{array}$ & $\begin{array}{c}\text { Здоровые } \\
\text { доноры } \mathrm{n}=35\end{array}$ & $\begin{array}{c}\text { р осн- } \\
\text { срав }\end{array}$ \\
\hline \multicolumn{5}{|c|}{ Ротовая жидкость } \\
\hline $\begin{array}{l}\text { HIF-1 } \alpha, \\
\text { мкг/мл }\end{array}$ & $37,5 \pm 1,16$ & $35,6 \pm 1,34$ & $29,2 \pm 2,99$ & $>0,05$ \\
\hline VEGF, пг/мг & $31,2 \pm 1,27$ & $24,6 \pm 1,83$ & $22,1 \pm 2,63$ & $<0,05$ \\
\hline \multicolumn{5}{|c|}{ Периферическая кровь } \\
\hline $\begin{array}{l}\text { HIF-1 } \alpha, \\
\text { мкг/мл }\end{array}$ & $83,2 \pm 5,43$ & $45,7 \pm 3,81$ & $33,2 \pm 1,84$ & $<0,001$ \\
\hline
\end{tabular}

Содержание в ротовой жидкости HIF-1 $\alpha$ у пациентов основной группы и группы сравнения практически не различалось. Это может быть связано со сложной белковой структурой гипоксия-зависимого фактора и трудностями его попадания в ротовую жидкость, поскольку HIF- $1 \alpha$ относится к тканевым факторам, регулирующим транскрипцию, и более информативен при исследовании его в ткани. У больных основной группы статистически значимые отличия концентраций в ротовой жидкости были установлены для ростового фактора VEGF. У пациентов основной группы в отличие от больных группы сравнения концентрация сосудистого фактора VEGF была повышена на 26,8\% (p<0,05). Таким образом, при развитии гнойных осложнений местно в биологических средах повышается 
уровень VEGF, способствующий ангио- и лимфогенезу, повышающий проницаемость сосудов.

Поскольку у больных изучаемых двух групп в ткани опухоли различие содержания HIF-1 $\alpha$ было выраженным, а в ротовой жидкости отличий не было, то было предпринято определение концентрации HIF- $1 \alpha$ в сыворотке крови (табл. 5). У больных основной группы по сравнению с группой сравнения уровень HIF-1 $\alpha$ в сыворотке крови был на $82,1 \%$ выше ( $<<0,001)$, а по сравнению со здоровыми донорами - на 150,6\% выше $(\mathrm{p}<0,001)$.

Итак, развитие гнойных воспалительных послеоперационных осложнений у больных раком СОПР сопряжено с повышением экспрессии в ткани HIF-1 $\alpha$ и его перемещением из цитоплазмы в ядро, активация процессов неоангиогенеза. Оценка же содержания HIF-1 $\alpha$ в ротовой жидкости была мало информативной, поскольку не отражала интенсивности тканевой экспрессии гипоксия-зависимого транскрипционного фактора. Более информативным является определение HIF-1 $\alpha$ фактора в сыворотке крови, что при дальнейшей разработке может быть использовано как неинвазивный диагностический маркер для прогнозирования течения послеоперационного периода у этой категории больных.

\section{Литература.}

1. Кирова, Ю.И. Влияние гипоксии на динамику содержания HIF-1альфа в коре головного мозга и формирование адаптации у крыс с различной резистентностью к гипоксии / Ю.И.Кирова // Патол. физиология и эксперим. терапия. -2012. -№3. -С.5155 .

2. Кононенко, В.И. Прогнозирование гнойно-септических осложнений у больных раком слизистой оболочки полости рта/ В. И. Кононенко, О. И. Кит, Е.Ф.Комарова, А. Ю.Максимов, А.А. Демидова // Научное обозрение. -2015. -№16. C.214-219.

3. De Lima P.O., Hypoxic condition and prognosis in oral squamous cell carcinoma./ P.O.De Lima, C.C.Jorge, D.T.Oliveira, M.C. Pereira // Anticancer research. —2014. Vol.34. -P.605-612. 
4. Huang, C. Association of increased ligand cyclophilin A and receptor CD147 with hypoxia, angiogenesis, metastasis and prognosis of tongue squamous cell carcinoma/ C. Huang, Z.Sun, Y.Sun, X. Chen et al. // Histopathology. -2012. -Vol.60. -P.793-803.

5. Kang, F.W. Hypoxiainducible factor- $1 \alpha$ overexpression indicates poor clinical outcomes in tongue squamous cell carcinoma/ F.W. Kang, Y. Gao, L. Que, J. Sun, Z.L. Wang, F.W. Kang // Exp. ther. med. -2013. -Vol.5. -P.112-118.

6. Lin, P.Y. Expression of hypoxia-inducible factor-1 alpha is significantly associated with the progression and prognosis of oral squamous cell carcinomas in Taiwan/ P.Y. Lin, C.H. Yu, J.T. Wang, H.H. Chen, S.J. Cheng, M.Y. Kuo, C.P. Chiang // J. Oral. pathol. med. 2008. -Vol.37. -P.18-25.

7. Perez-Sayans, M. Hypoxia-inducible factors in OSCC./ M.Perez-Sayans, J.M.Suárez-Peñaranda, G.D.Pilar, F. Barros-Angueira //Cancer letters. - 2011. - Vol. 313, N1/ - P.1-8.

8. Semenza, G.L. Hypoxia-inducible factors in physiology and medicine/ G.L. Semenza // Cell. 2012. T. 148. №3. - C. 399-408.

9. Semenza, G.L. Oxygen sensing, hypoxia-inducible factors, and disease pathophysiology./ G.L. Semenza // Ann. rev. pathol. -2013. -Vol.7. -P.7.

10. Shang, Z.J. Up-regulation of serum and tissue vascular endothelial growth factor correlates with angiogenesis and prognosis of oral squamous cell carcinoma/ Z.J. Shang, J.R. Li, Z.B. Li // J. Oral. maxillofac. surg. -2007. -Vol.65. -P.17-21.

11. Myllyharju, J. Hypoxia-inducible factor prolyl 4-hydroxylases: common and specific roles/ J.Myllyharju, P.Koivunen // Biol. Chem. -2013. -Vol. 394. -N4. -P.435-448.

\section{References.}

1. Kirova, Ju.I. Vlijanie gipoksii na dinamiku soderzhanija HIF-1al'fa v kore golovnogo mozga i formirovanie adaptacii u krys s razlichnoj rezistentnost'ju k gipoksii / Ju.I.Kirova // Patol. fiziologija i jeksperim. terapija. -2012. -№3. -S.51-55.

2. Kononenko, V.I. Prognozirovanie gnojno-septicheskih oslozhnenij u bol'nyh rakom slizistoj obolochki polosti rta/ V. I. Kononenko, O. I. Kit, E.F.Komarova, A. Ju.Maksimov, A.A. Demidova // Nauchnoe obozrenie. -2015. -№16. -S.214-219.

3. De Lima P.O., Hypoxic condition and prognosis in oral squamous cell carcinoma./ P.O.De Lima, C.C.Jorge, D.T.Oliveira, M.C. Pereira // Anticancer research. —2014. — Vol.34. -P.605-612.

4. Huang, C. Association of increased ligand cyclophilin A and receptor CD147 with hypoxia, angiogenesis, metastasis and prognosis of tongue squamous cell carcinoma/ $\mathrm{C}$. Huang, Z.Sun, Y.Sun, X. Chen et al. // Histopathology. -2012. -Vol.60. -P.793-803.

5. Kang, F.W. Hypoxiainducible factor- $1 \alpha$ overexpression indicates poor clinical outcomes in tongue squamous cell carcinoma/ F.W. Kang, Y. Gao, L. Que, J. Sun, Z.L. Wang, F.W. Kang // Exp. ther. med. -2013. -Vol.5. -P.112-118.

6. Lin, P.Y. Expression of hypoxia-inducible factor-1 alpha is significantly associated with the progression and prognosis of oral squamous cell carcinomas in Taiwan/ P.Y. Lin, C.H. Yu, J.T. Wang, H.H. Chen, S.J. Cheng, M.Y. Kuo, C.P. Chiang // J. Oral. pathol. med. 2008. -Vol.37. -P.18-25.

7. Perez-Sayans, M. Hypoxia-inducible factors in OSCC./ M.Perez-Sayans, J.M.Suárez-Peñaranda, G.D.Pilar, F. Barros-Angueira //Cancer letters. - 2011. - Vol. 313, N1/ - P.1-8.

8. Semenza, G.L. Hypoxia-inducible factors in physiology and medicine/ G.L. Semenza // Cell. 2012. T. 148. №3. - S. 399-408. 
9. Semenza, G.L. Oxygen sensing, hypoxia-inducible factors, and disease pathophysiology./ G.L. Semenza // Ann. rev. pathol. -2013. -Vol.7. -P.7.

10. Shang, Z.J. Up-regulation of serum and tissue vascular endothelial growth factor correlates with angiogenesis and prognosis of oral squamous cell carcinoma/ Z.J. Shang, J.R. Li, Z.B. Li // J. Oral. maxillofac. surg. -2007. -Vol.65. -P.17-21.

11. Myllyharju, J. Hypoxia-inducible factor prolyl 4-hydroxylases: common and specific roles/ J.Myllyharju, P.Koivunen // Biol. Chem. -2013. -Vol. 394. -N4. -P.435-448. 